\title{
Bocio endotorácico asociado a tiroiditis de Hashimoto como causa de fiebre de origen desconocido, reporte de caso
}

\author{
Jaider Luis Saurith Monterrosa ${ }^{1}$, Rafael Pila Peláez ${ }^{2}$, Rafael Pila Pérez $z^{3}$, Pedro Rosales Torres ${ }^{4}$
}

\author{
${ }^{1}$ Residente tercer Año Medicina Interna, Hospital Manuel Ascunce \\ Domenech \\ ${ }^{2}$ Especialista segundo Grado Medicina Interna, Profesor Auxiliar \\ Interna, Hospital Manuel Ascunce Domenech \\ ${ }^{3}$ Especialista segundo Grado Medicina Interna, Profesor Titular \\ Interna, Hospital Manuel Ascunce Domenech \\ ${ }^{4}$ Especialista primer grado anatomía patológica; Instructor \\ Correspondencia: Dr. Rafael Pila Pérez \\ Email: jaidersaurith@hotmail.com \\ Fecha de recepción: 21/12/2017 \\ Fecha de aceptación: 12/05/2018
}

\section{Resumen}

$\mathrm{L}$ a tiroiditis de Hashimoto es una enfermedad de frecuencia relativa en nuestro medio, su presentación como fiebre de origen desconocido (FOD) es excepcional como se demuestra por la ausencia de bibliografía al respecto, los estudios de laboratorio clínico descartan todas las posibles etiologías infecciosas, inmunes y oncológicas, el estudio por imágenes orientó el diagnóstico, el cual fue comprobado por los estudios histopatológicos después de la tiroidectomía total.

\section{Introducción}

El término fiebre de origen desconocido (FOD) fue establecido arbitrariamente por Petersdorf y Benson ${ }^{(1)}$ como fiebre de $38{ }^{\circ} \mathrm{C}$ o más, rectal, durante al menos tres semanas y que permanece sin diagnosticar tras una semana de estudios en un centro hospitalario. Weinstein y Field ${ }^{(2)}$ hacen una revisión crítica del tema y consideran más apropiado el término para los pacientes que cursan con fiebre de $38{ }^{\circ} \mathrm{C}$ durante tres o más semanas, cuya causa no se ha descubierto con los datos obtenidos en la historia clínica, examen físico y la práctica de análisis de sangre, orina y radiografía de tórax.

Las causas de FOD se agrupan así:

1. Un $40 \%$ de los casos corresponden a procesos infecciosos.

2. Un $20 \%$ se corresponden con neoplasias.

3. Otro $20 \%$ es atribuido a conectivopatías.
4. El último grupo es una miscelánea de enfermedades hematológicas, vasculares, inmunológicas, etc.

En un $10 \%$ de los enfermos, la causa es desconocida. Desde entonces han sido numerosos los trabajos realizados y las series publicadas sobre esta enfermedad ${ }^{(3)}$.

Se presenta el caso de FOD debido a una tiroiditis de Hashimoto $(\mathrm{TH})$ que es una enfermedad frecuente en el sexo femenino $15 \%-20 \%$ y que puede aparecer a cualquier edad, aunque con mayor frecuencia entre los 30 y los 50 años siendo muy frecuente en Estados Unidos y Reino Unido donde su incidencia se cifra en 0,3-1,5 por mil habitantes, siendo la causa de hipotiroidismo bociógeno en las regiones con aporte normal de yodo ${ }^{(4)}$.

A continuación, hacemos presentación de un caso ingresado en el servicio de medicina interna de paciente de mediana edad con FOD y en quien se evidenció como causa una tiroiditis de Hashimoto, lo cual es extremadamente raro.

\section{Reporte del caso}

Paciente femenina de raza negra de 57 años, con antecedentes de hipertensión esencial e hipotiroidismo, sin antecedentes familiares de importancia médica. Como datos de interés, trabajó en labores administrativas en zona selvática en la Amazonía venezolana, hacia tres meses.

El tratamiento domiciliario con hidroclorotiazida una tableta de $25 \mathrm{mg}$ diaria, enalapril tabletas de $20 \mathrm{mg}$ una cada 12 horas y levotiroxina una tableta de 0,1 mg diaria.

Consultó inicialmente al hospital de su área de salud por cuadro clínico de una semana de evolución, consistente en picos febriles de patrón ondulante asociado a tos seca quintosa, en ese momento se le dio diagnóstico de bronquitis aguda, indicándole azitromicina $500 \mathrm{mg} /$ día durante cinco días sin mejoría; posteriormente, la hospitalizaron y le dieron manejo bajo el diagnóstico de neumonía comunitaria con cefalosporina de tercera generación durante un periodo de 10 días. Todo lo anterior sin respuesta terapéutica. La paciente decidió egresar de forma voluntaria del centro asistencial hasta evolucionar cuadro por tres meses sin cambio de su sintomatología, recurriendo a nuestro servicio, donde se ingresa para estudio. 
La paciente nos refiere que durante su estancia en Venezuela se le practicaron estudios hormonales del tiroides que dieron anticuerpos antiperoxidasa positivos, además refiere dolor y dificultad al ingerir alimentos sólidos y disnea ocasional.

Al examen físico, presenta palidez cutaneomucosa discreta, aparato cardiopulmonar, abdomen, neurológico, ginecológico y osteomuscular sin alteraciones, fondo de ojo y otoscopia normal, al examen del cuello (maniobra de Quervain, Lahey y Crile negativa); el único dato positivo al examen físico fue el signo de Pemberton, el cual es muy sugestivo de bocio endotorácico.

El estudio analítico de hemoglobina 9,8 g/l, leucocitos $8,500 \mathrm{~mm}^{3}$ con diferencial normal, proteína $\mathrm{C}$ reactiva elevada, eritrosedimentación $110 \mathrm{~mm} / \mathrm{h}$, ionograma, enzimas hepáticas, amilasa, creatinina, glucemia, lipograma, ácido úrico, proteínas totales, LDH, CK total, conteo de plaquetas y conteo de reticulocitos dentro de los parámetros normales, lámina periférica ligera hipocromía. VDRL, ELISA VIH, hemocultivos seriados, urocultivo, coprocultivo, anticuerpo contra hepatitis $\mathrm{C}$, antígeno de superficie hepatitis $\mathrm{B}$, exudado faríngeo, gota gruesa, ANA, crioglobulinas, complemento, Paul Bunnel y test de Davinson negativos, electrocardiograma normal, ecocardiograma normal, ultrasonido abdominal y ginecológico normal, medulograma y medulocultivo normal, prueba de función tiroidea T4120 nmol /L (VN 50-144) T3 0,94 nmol/L (VN 0,92-2,78), TSH: $3 \mathrm{mcm} / \mathrm{mL}$ (VN:0,5-5,0). Radiografía de tórax posteroanterior y lateral (figura 1).

Ultrasonido de tiroides con proyecciones endotorácicas que arrojó como resultado: lóbulo izquierdo aumentado de volumen con proyecciones endotorácicas de $74 \times 43 \mathrm{~mm}$, restos del tiroides de aspecto multinodular. Impresión Diagnóstica Bocio endotorácico,

Al describirnos estos hallazgos en pro de descartar que el desplazamiento traqueal descrito en la radiografía de tórax fuera por componente esofágico se toma la decisión de solicitar esofagograma, que se encontró dentro de los parámetros normales (figura 2). Tomografía axial computarizada de tórax (figura 3).
Figura 2. Se observa columna de bario con intelectaciones normales y fisiológicas, esofagograma dentro de los parámetros normales

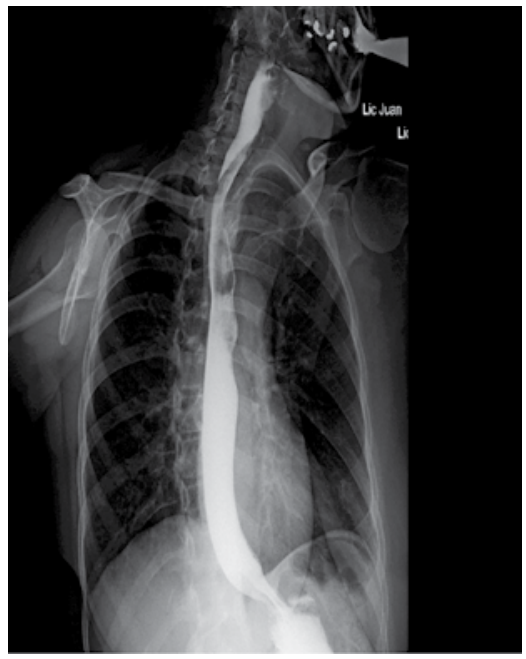

Figura 3. TC de pulmón simple: A nivel del mediastino superior aumento del volumen del lóbulo tiroideo izquierdo 81x48 $\mathrm{mm}$, proyecciones endotorácicas con desplazamiento traqueal hacia la derecha. (Ver flecha)

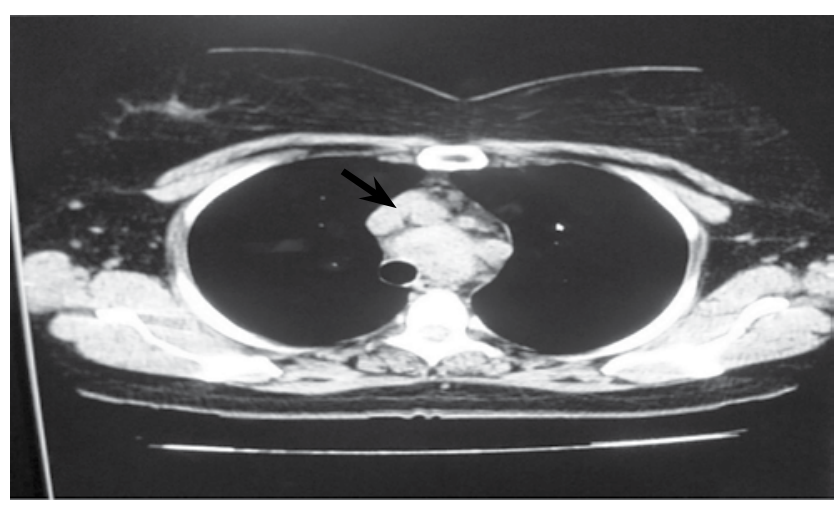

Figura 1. Radiografía de tórax AP Y LAT: desplazamiento de la tráquea a la derecha con el aspecto de compresión extrínseca, no alteraciones pleuropulmonares
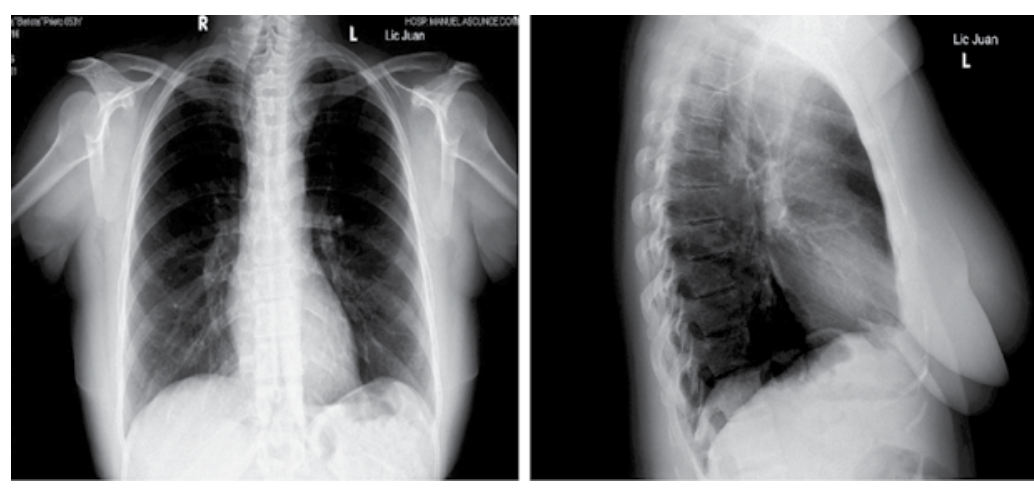

Posteriormente se realizó tiroidectomía total con extracción de proyecciones endotorácicas, procedimiento sin complicaciones (figuras 4 y 5), se mantuvo a la paciente hospitalizada durante una semana posterior al procedimiento, con resolución total de la sintomatología por la cual consultó. El resultado de la biopsia y el estudio histopatológico (figura 6) fueron compatibles con tiroiditis de Hashimoto no signos de malignidad, paciente la cual seguimos de manera ambulatoria y durante todos los chequeos han sido normales sin presentar fiebre. 
Figuras 4 y 5 . Se observa glándula de tiroides con aumento difuso de tamaño, con predominio de lóbulo tiroideo izquierdo de 8 x $5 \mathrm{~cm}$ de coloración parda-rojiza, consistencia firme y superficie ligeramente nodular
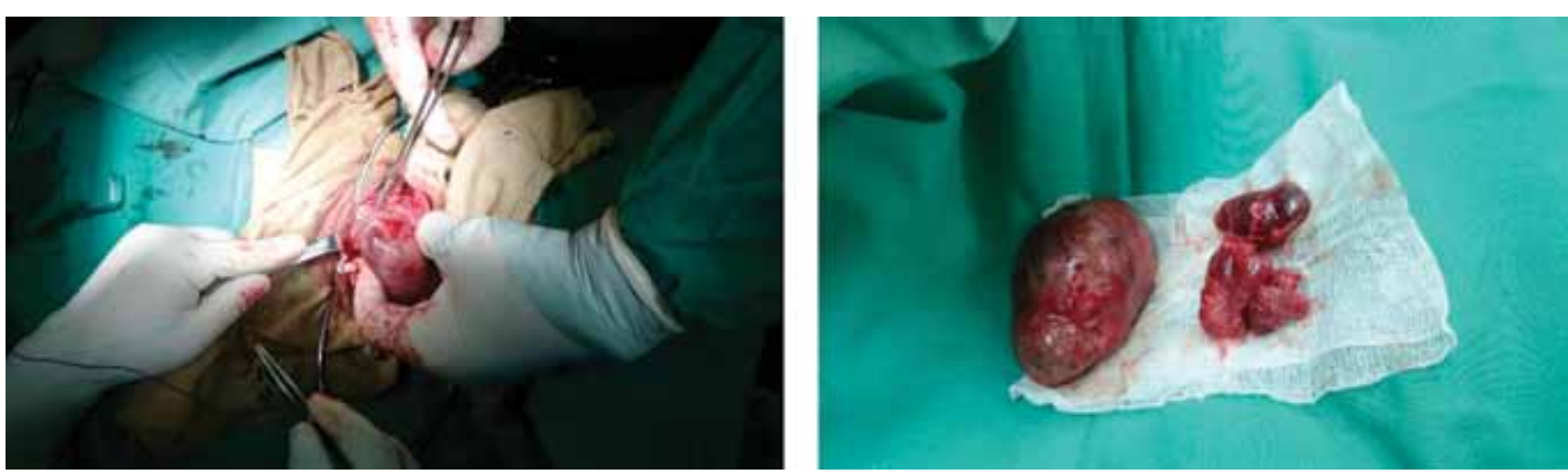

Figura 6. Se observa atrofia de folículos tiroideos, infiltrado inflamatorio crónico a predominio de linfocitos y centros germinales desarrollados. Datos compatibles con tiroiditis de Hashimoto

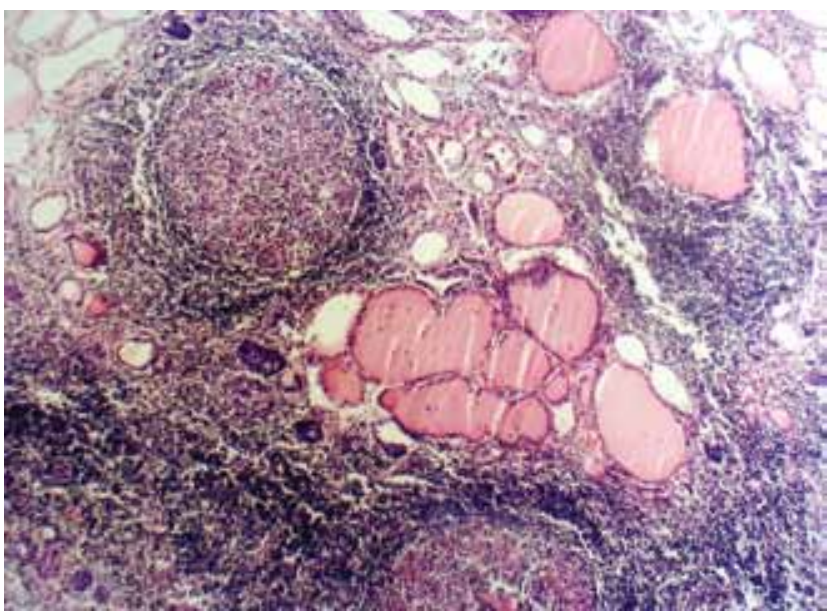

\section{Discusión}

Existen enfermedades cuya presentación clínica es muy característica e infrecuentemente se presentan como un síndrome febril, por lo que son difíciles de diagnosticar. Dentro de las FOD existen aproximadamente más de 200 trastornos como diagnósticos diferenciales que incluyen cuadros autoinmunes; como causa de esta entidad se encuentran las enfermedades del tiroides, principalmente las tiroiditis agudas y subagudas, las cuales cursan con fiebre a veces de causa desconocidas ${ }^{3-5}$

Sin embargo, las tiroiditis crónica, como la $\mathrm{TH}$, no se reportan como FOD, como lo hemos observado nosotros que después de un rastreo bibliográfico exhaustivo no hemos encontrado referencias al respecto.

Existen una serie de formas clínicas atípicas y poco frecuente de la TH como la pseudotirotoxicosis de comienzo subagudo a la que se asocia con oftalmopatía de Graves, otra entidad curiosa es la denominada "hashitoxicosis" en la que coexisten hiperfunción e histología de TH, todo esto indica el espectro de la patología tiroidea inmunomunitaria ${ }^{(4)}$.

En esta paciente con una FOD de larga data y a quien se han practicado múltiples exámenes relacionados con la misma y que tiene como diagnóstico una TH de varios años demostrado por pruebas funcionales del tiroides y anticuerpos antiperoxidasa, los cuales son positivos en esta entidad en el $97 \%$ de los $\operatorname{casos}^{(4)}$. Tuvimos presente la posibilidad de un proceso de malignidad en el curso de la misma.

En nuestra paciente se constató por estudio de imagen un bocio endotorácico de gran tamaño, simétrico, como en algunos casos está lo bastante localizado como para hacer pensar en una neoplasia ${ }^{(6)}$. Como lo sospechamos en este caso, la glándula tiroides no contiene tejido linfoide nativo, el tejido linfoide intratiroideo aparece en varias condiciones patológicas de las cuales la más evidente es en el curso de patología tiroidea autoinmune, como en el caso de la tiroiditis crónica autoinmune de Hashimoto ${ }^{(7)}$, un porcentaje significativo de linfoma primario de tiroides advierte sobre una tiroiditis autoinmune de base ${ }^{(8)}$, esta asociación está presente en alrededor del 50\% de los casos, siendo el único factor de riesgo conocido ${ }^{(7-8)}$. Dentro de los pacientes con $\mathrm{TH}$, el riesgo de desarrollar linfoma tiroideo es 60 veces más frecuente que en los pacientes sin tiroiditis; por lo tanto, la frecuencia de linfoma primario de tiroides parece ser más elevada en áreas con alta prevalencia de tiroiditis. Muchos pacientes tienen síntomas y signos de compresión traqueal o esofágica, lo que ocasiona disfagia, estridor y edema facial ${ }^{(3-5)}$; en esta paciente se presentó disnea y disfagia a los alimentos sólidos, se constató un signo que se observa en casos de bocio endotorácico llamado signo de Pemberton que orienta a esta localización, en el laboratorio no se encontró ninguna alteración específica para el diagnóstico. Algunos pacientes se encuentran hipotiroideos y muchos presentan anticuerpos antiperoxidasa y antitiroglobulina positivos indicativos de $\mathrm{TH}^{(4)}$, en nuestro caso el primer examen fue positivo en un estudio anterior de cinco meses. 
Por los estudios de imágenes no pueden distinguirse las tiroiditis, carcinomas o linfomas pero, sin embargo, estos estudios ayudan a evaluar la extensión de la enfermedad, planificar la terapéutica y monitorear la respuesta al tratamiento ${ }^{(10)}$. La ecografía y la punción aspirativa con aguja fina son los estudios utilizados para evaluar una tumoración del tiroides ${ }^{(6-8)}$. En nuestra paciente, la ecografía del tiroides permitió demostrar el aumento de volumen del lóbulo izquierdo con proyecciones endotorácicas y el aspecto multinodular, lo cual fue corroborado por la tomografía axial computarizada. No se realizó biopsia por aspiración con aguja fina por la condición de bocio endotorácico y manifestaciones compresivas.

La punción con aguja gruesa o la biopsia excisional es de provecho en los casos que no puedan resecarse por tiroidectomía total, son necesarios a fin de obtener suficiente material para el diagnóstico histológico definitivo y, en ocasiones, con la complementación de la inmunohistoquímica ${ }^{(7-10-11)}$.
El tratamiento quirúrgico (tiroidectomía total) es de utilidad ante los cuadros compresivos, específicamente ante el compromiso de la vía aérea, su gran tamaño y compresión esofágica ${ }^{(7-9-11)}$. Nuestra paciente después de esta terapéutica se ha mantenido asintomática con la dosis complementaria de levotiroxina sódica.

\section{Conclusiones}

La comunicación de casos con esta afección facilitará el conocimiento y mejoría del diagnóstico, evitará retrasos y exámenes innecesarios que en muchas ocasiones son de alto costo y generan grandes molestias al paciente.

\section{Conflicto de intereses: Ninguno}

\section{Referencias}

1. Petersdorf R, Benson P. Fever of unexplained origin: report on 100 cases. Medicine (Baltimore). 1960;40:130.

2. Weinstein L, Fields B. Fever of obscure origin; Seminars in infectious disease. New York: Srattoninter continental Medical Book; 1988. Pág. 108.

3. Pila Pérez R, Pila Peláez R, Campo Prince D; Tiroiditis de subaguda como causa de fiebre de origen desconocido Rev. Med Camagüey 2006, vol. 5 115:120.

4. Lucas Martín, M. Puig Domingo, J. L. Reverter Calatayud; enfermedades del tiroides. Farreras - Rozman XVII edición 2012 E lsevier España, Pag 2356-8

5. Cortez Mijares l, Martínez Lastre A, Plain Pozos C, Tiroiditis subaguda como causa de síndrome febril prolongado. Presentación de un caso. Revista Electrónica de las Ciencias Médicas en Cienfuegos ISSN: 1727-897X Medisur 2012; 10(6) 519-521.

6. Contran R, kumar v, Collins T. El sistema endocrino $<<$ hipotiroidismo $>>$ En patología Robins y Cotran. Patología estructural y funcional, McGraw-Hill interamericana, Pág. 1179.
7. Chigael G,Moloeznik L, Nebel E, Quriroga S, Olguin N, Brunas . Linfoma primario de tiroides: Diagnostico en dos casos clínicos _ Gland Tir Parar 2008(17) 34-38.

8. Pila Perez R, Pila Pelaez R, Rosala P, Holguin V. Linfoma primario de tiroides. ORL Dips (Esp) 2005 (3):164-8.

9. Mazzaferri E, Oertel Y, primary malignant thyroid lymphoma and related lymphoproliferative disorders. Endocrine tumors Mazzaferri : Samaan eds Boston; Blackwell Scientific , 1993:348-350.

10. Podoloff, DA. Is there a place for routine surveillance using sonography, CT or MR imaging for early detection (notably lymphoma) of patients affected by Hashimoto's thyroiditis? AJR Am J Roentgenol 1996; 167:1337-8.

11. Bergoglio LM, Mestman JH. Guía de consenso para el diagnóstico y seguimiento de la enfermedad tiroidea. Acta Bioquím Clín Latinoam. 2007; 41(1):87-119. 